\title{
HEURÍSTICA CREATIVA Y MÉTODO INDICIAL EN LOS CUENTOS DE EDGAR ALLAN POE Javier Ayala Calderón*
}

RESUMEN: Con antecedentes directos en la medicina e incluso en la cacería, en el siglo XIX el método indicial tuvo gran auge como manera científica de aproximarse al conocimiento del mundo a partir de síntomas o huellas. En la literatura se manifestó en el surgimiento de la novela policíaca con Edgar Allan Poe, pero el modo en que se procede indicialmente en las ciencias y en la literatura presenta diferencias de fondo que deben analizarse para no caer en simplificaciones con respecto a sus semejanzas.

Palabras Clave: Método indicial, heurística creativa, cuento de raciocinio, Edgar Allan Poe, novela policíaca.

\section{CREATIVE HeURISTICS AND THE INDUCTIVE \\ METHOD IN EDGAR ALLAN POE'S TALES}

ABSTRACT: In the nineteenth century, the inductive method, originating from medicine and hunting, reached its peak. Through symptoms and fingerprints had great success as a scientific method to learn knowledge about the world. In literature, it made its presence known in the detective novels of Edgar Allan Poe; however the inductive method in the sciences and literature shows differences that need to be analyzed so that we don't make simplistic statements regarding their similarities.

KEYWORDS: Inductive method, creative heuristics, tales of ratiocination, Edgar Allan Poe, detective novels.
RECEPCIÓN: 28 de octubre de 2014.

ACEPTACIÓN: 24 de noviembre de 2015.
* Departamento de Historia, Universidad de Guanjuato. 


\author{
HEURÍSTICA CREATIVA Y \\ MÉTODO INDICIAL EN LOS \\ CUENTOS DE EDGAR ALLAN POE
}

\section{Introducción}

De acuerdo con el historiador italiano Carlo Ginzburg, hacia finales del siglo XIX surgió en el ámbito de las ciencias humanas un paradigma o modelo epistemológico más tarde conocido como indiciario o indicial, utilizado ya desde entonces por varios personajes como Giovanni Morelli, Arthur Conan Doyle y Sigmund Freud para explicar realidades concretas a partir de indicios.

En un giro demasiado forzado de su argumento, Ginzburg encuentra el anclaje de este sistema en la sintomatología clínica, debido a que estos tres personajes tenían algún tipo de relación con la medicina, pero terminaba reconociendo que esta práctica era expresión de una manera cinegética de ver el mundo desde los orígenes de la humanidad, los cuales equivalían, en última instancia, a contar los pormenores de una historia. Para Ginzburg, lo que caracteriza al saber cinegético es su capacidad para remontarse a partir de datos experimentables, pero aparentemente secundarios, hasta llegar a una realidad compleja, no experimentada en forma directa, y agrega que el observador organiza esos datos de tal manera que consigue una secuencia narrativa. ${ }^{1}$

Por supuesto, todo depende de la parte de la secuencia de huellas en que

${ }^{1}$ Carlo Ginzburg, "Indicios. Raíces de un paradigma de inferencias indiciales", en Mitos, emblemas e indicios, 1999, Barcelona, Gedisa, traducción de Carlos Catroppi, p. 144. 
nos encontremos, pues aunque en general una huella es indicio de algo ya ocurrido, no es lo mismo narrar prospectivamente que en retrospectiva. Narrar prospectivamente requiere dar seguimiento al acontecer en el orden en el que los hechos reconocidos se sucedieron y concatenaron hasta conocer un desenlace, mientras que narrar retrospectivamente implica retroceder sobre los pasos del actor de los hechos para conocer los antecedentes que explican un desenlace ya al menos conocido en parte. Incluso podríamos manejar formas mixtas de lectura partiendo, por ejemplo, de un punto central para avanzar en ambas direcciones y encontrar los antecedentes que, a su vez, explican las circunstancias que se conocerán después.

El saber cinegético, de hecho, tenía como objetivo original el primer modelo, la narración cronológica. No se trataba de contar retrospectivamente una historia conocida, sino de reconstruir paso a paso una historia que se iba conociendo a medida que se avanzaba en el descubrimiento de las pistas, mientras que el relato posterior acerca de este procedimiento podía adoptar cualquier otro orden (dependiendo de la pericia del narrador), incluyendo la retrospectiva.

Es el punto desde donde nosotros partiremos.

\section{Qué es el indicio}

María Elena Bitonte, en un texto presentado en las III Jornadas "Peirce en Argentina”, afirma: "Un indicio es un detalle, la estructura, una totalidad". En efecto, si entendemos la totalidad como una organización de factores, como una estructura, el indicio es una parte de ella como una señal que apunta hacia el todo. Lo que la teoría indicial plantea es, pues, un examen de las evidencias, su naturaleza y su funcionamiento. Por consiguiente, aquí entenderemos el indicio como una huella, un rastro, una pista, una señal que apunta, que indica (por eso se llama "indicio") hacia una realidad que se asume como su origen, pero que no está incluida evidentemente en él. Y por método indicial entenderemos al procedimiento conjetural que partiendo de estas señales busca remontarse hasta las razones de su producción "ubicándose en las antípodas de la ciencia natural moderna, fundada por Galileo (1564-1642), basada en el cálculo matemático y el método experimental".2

${ }^{2}$ María Elena Bitonte, "Huellas. De un modelo epistemológico indicial", en III Jornadas "Peirce en Argentina", 11-12 de septiembre de 2008, consultado en $<$ http://www.unav.es/gep/IIIPeirceArgentinaBitonte.html\#nota1 $>$. 
NOTAS

\section{Los cuentos de raciocinio}

Para una gran cantidad de seguidores, la narrativa de detectives es un género mucho más antiguo de la fecha habitual situada en el siglo XIX, y no faltan quienes se animan a remontarlo a los textos de la Biblia, con el asesinato de Abel a manos de su hermano Caín, o bien a la literatura china de ficción policiaca "Gong An" (Registros de casos en un tribunal de derecho público). No obstante, en la tradición occidental, la primera figura del mundo literario que dio forma a los relatos detectivescos fue el estadounidense Edgar Allan Poe (1809-1849), que, por consiguiente, es para muchos el inventor del género en el sentido estricto del término.

Es cierto que los cuentos detectivescos de Poe (que él denominaba "cuentos de raciocinio") no son más que una pequeña parte de sus relatos, lo cual apoya la hipótesis de la emergencia del género en ese momento, tomando en cuenta la proporción que estos ocuparán en la obra de autores posteriores.

En todo caso, dentro de la producción de Poe el cuento de raciocinio tiene un contexto comprensible, considerando la naturaleza eminentemente cerebral de sus explicaciones en muchos otros relatos, pese a las temáticas fantásticas que abordan. No de otra manera podemos, por ejem- plo, citar los casos de "La aventura sin par de un tal Hans Pfall" (1835), con aquella larga nota en la que se dedica a refutar las "observaciones" de la Historia lunar, de Mr. Locke (aparecida en el New York Sun semanas antes la publicación de la obra de Poe en el Southern Literary Messenger, de Richmond, Virginia); "El Jugador de Ajedrez de Maelzel” (1836), que intenta metódicamente resolver el misterio de una supuesta máquina capaz de ganarle "casi siempre" a los seres humanos en el juego; "El escarabajo de oro" (1843), en el que se plantea el desciframiento de una clave para encontrar un tesoro; "La esfinge" (1846), que explica las circunstancias de una aparición monstruosa (pero no sobrenatural) en términos estrictamente físicos y matemáticos de perspectiva, etc., por solo citar los casos más evidentes y dejando a un lado sus intentos por explicar la belleza paisajista en términos geométricos y matemáticos, como hace en "La quinta de Landor" y "La posesión de Arnheim".

En este contexto cerebral, ávido de encontrar respuestas mensurables y exactas, de plantear un mundo comprensible a partir del orden y la evidencia (que llamó la atención de Charles Baudelaire en su biografía de Poe), sus obras detectivescas más reconocidas adquieren todo su sentido y su razón de ser marcando 
verdaderos hitos en la narrativa del género.

En "Los asesinatos de la calle Morgue" (1841) se narra la investigación sobre el asesinato de dos mujeres ocurrido en París en una habitación cerrada por dentro. El caballero C. Augusto Dupin, primer detective moderno de la narrativa occidental de ficción, debe enfrentarse, además, a las extravagantes y sangrientas características del crimen, muy del gusto de la novela gótica entonces en boga. El siguiente cuento en la fila es "El misterio de María Rogêt" (1842), en el que el asunto es la desaparición de la dependienta de una perfumería, el descubrimiento de su cadáver en las aguas del río Sena y las investigaciones a distancia realizadas por Dupin, basándose en las notas periodísticas. Finalmente, en "La carta robada" (1845) se narra la manera en la que Dupin encuentra y recupera una carta personal que compromete a una dama relacionada con las altas esferas de la política francesa haciendo gala de un método basado en el análisis de los datos existentes, el "encuentro" de los elementos significativos (indicios), que compila para ofrecer una explicación particular, es decir, un método analítico-sintético de tipo abductivo.

¿De dónde viene el interés de Poe por estos procedimientos en sus cuentos de raciocinio? Casi con toda certeza, de las ciencias naturales que menciona constantemente y no de manera directa de la tradición jurídica y el Derecho procesal de su época, a los cuales Poe jamás alude, si bien es cierto que estos últimos se desarrollaban paralelamente a los avances de la ciencia y requerían pruebas confiables a medida que se prohibía la tortura de los presos para obtener confesiones. ${ }^{3}$ Fascinado por los avances de la ciencia (la electricidad, los autómatas, las máquinas voladoras, la medicina, etc.), el temperamento de Poe lo llevó a tratar de incorporar la imaginación poética a las inquietudes racionalistas con respecto al mundo, que en general se encontraban en plena ebullición en vista de la desintegración del idealismo alemán a principios del siglo XIX y el surgimiento del positivismo.

\section{El programa positivista}

Los excesos a los que había llegado el idealismo en las primeras décadas del siglo XIX, con sus sistemas cerrados de interpretación de los orígenes y desarrollo de las sociedades humanas, escondidos tras ejemplos arbitrarios que disimulaban su apriorismo (lo cual condujo a Popper a su par-

${ }^{3}$ Cesare Becaria, Tratado de los delitos y de las penas, 2004 (edición facsimilar de la de 1774 en Madrid por D. Joachin Ibarra, traducido del italiano por Juan Antonio de las Casas), Valladolid, Maxtor, pp. 66-72 y 77-95. 
ticular definición de "historicismo"), ${ }^{4}$ había desembocado en un hastío de la metafísica. La gente culta sentía la necesidad apremiante de apartarse de las construcciones mentales arbitrarias para atenerse a las cosas mismas, a la realidad entendida como lo que podía experimentarse a través de los sentidos y era susceptible de comprobación y medida. ${ }^{5}$

Tras la muerte de Hegel (17701831), respetado y venerado hasta el fin por sus contemporáneos, Augusto Comte publicó entre 1830 y 1842 una serie de textos que conformaron su Curso de filosofía positiva. Ahí Comte propuso una interpretación realista del mundo basándose exclusivamente "en las nociones a posteriori". ${ }^{6}$ En este sistema, la imaginación quedaba subordinada a la observación y la mente humana tenía que atenerse a las "cosas", limitándose a "lo puesto o dado", sin preguntarse por sus causas o sus principios fundamentales. ${ }^{7}$ Por lo mismo, sus interpretaciones sociales no resultaban nunca absolutas, sino relativas a la

${ }^{4}$ Según Popper, el historicismo asumía que la tarea de las ciencias sociales es poner al descubierto la ley de evolución de la sociedad, para predecir su futuro; véase Karl Popper, La miseria del historicismo, 1992, Madrid, Alianza, traducción de Pedro Schwartz, p. 119. Como puede notarse, en realidad se refería al positivismo historizante.

${ }^{5}$ Julián Marías, Historia de la filosofia, 1997, México, Alianza, p. 331.

${ }^{6}$ Angèle Kremer-Marietti, El positivismo, 1997, México, Cruz O, p. 7.

${ }^{7}$ Marías, op. cit., p. 339. situación del observador, la cual está marcada por las condiciones de la existencia individual y grupal $\mathrm{y}$, por lo tanto, por su historia. ${ }^{8}$ El positivismo, nombre dado a su sistema por basarse en un conocimiento no especulativo, buscaba, pues, solo los hechos y las leyes que los gobernaban, y se distinguía así del empirismo clásico por cerrarse, de hecho, al análisis crítico del conocimiento común. $^{9}$

Durante siglos la jerarquía de las ciencias había estado encabezada por las matemáticas, ${ }^{10}$ que había llegado a ser considerada "la razón por excelencia", como recuerda el fiel compañero del caballero Dupin. ${ }^{11}$ Sin embargo, con la formulación cada vez más precisa del método científico en el siglo XVIII, los practicantes de las ciencias naturales se volvieron también cada vez más conscientes de su autonomía con respecto al conocimiento empírico común, a las matemáticas y a la filosofía. ${ }^{12}$ Como afirma Carlos-Ulises Moulines, la generación de Newton y Leibniz no habría comprendido la distinción actual entre filósofos y científicos, y como argu-

${ }^{8}$ Ibid., pp. 340 y 343.

${ }^{9}$ Carlos-Ulises Moulines, "La génesis del positivismo en su contexto científico", Dianoia, vol. XXI, núm. 21, 1975, p. 34.

${ }^{10}$ Angèle Kremer-Marietti, op. cit., p. 7.

${ }^{11}$ Edgar Allan Poe, "The purloined letter", en The works of Edgar Allan Poe, vol. II, 1884, Nueva York, A.C. Armstrong and Son, p. 407.

${ }^{12}$ Moulines, op. cit., p. 33. 
mento de ello basta con recordar que "Newton todavía consideraba que su obra era un primer paso para resolver problemas generales, ontológicos, metafísicos e incluso teológicos". ${ }^{13}$ Edgar Allan Poe, racionalista tardío, era también un romántico tardío y compartía esta manera de pensar, como puede notarse, por ejemplo, en sus cuentos metafísicos "E1 coloquio de Monos y Una" (1845), "El poder de las palabras" (1845) y, sobre todo, en el abstruso ensayo Eureka (1848).

Por el contrario, los nuevos investigadores asumieron la explicación científica del mundo "como algo radicalmente nuevo y distinto de los tipos anteriores de explicación" y desembocaron en la actitud "filocientífica" del positivismo, en la que conservaron a las matemáticas más como el lenguaje para comunicarse entre ellos, que como una ciencia aparte. ${ }^{14}$

Sin dejar de tener una alta estima por el cálculo matemático, para Poe la rigidez de esta disciplina requería su contraparte poética para poder hablar de un conocimiento verdaderamente profundo. ${ }^{15}$ Para Poe, como para Newton y Leibniz, la capacidad de imaginar, enemiga del conocimiento positivo, era la esencia de la búsqueda misma. Por ese motivo,

${ }^{13}$ Ibid., p. 34, nota 3.

${ }^{14}$ Ibid., p. 38.

${ }^{15}$ Poe, "The purloined letter", en op. cit., pp. 406-407.
Poe, nacido en 1809 , se encontró en la plenitud de su madurez intelectual sumido en un ambiente cientificista esquemático y materialista en el que no encajaba, pero con el que compartía como principio fundamental el racionalismo heredado del siglo anterior. Ese es el motivo por el que en sus relatos de detectives la averiguación de la verdad se realiza mediante un proceso complejo que combina a partes iguales intuición, astucia y lógica.

\section{Especulación y conjetura}

La cuestión del crimen era para Poe como el ajedrez o el whist, "where mind struggles with mind", ${ }^{16}$ un caso de cálculo matemático o, mejor, de geometría en el que el plan urdido hacia adelante por el criminal, prospectivamente, hasta desembocar en el crimen, debe ser recorrido en sentido inverso, punto por punto, desde el crimen hasta llegar a la mente criminal detrás de él. Los hechos, situándose en el plano de la más pura abstracción, al acontecer de un modo conocido, remiten retrospectivamente al momento en el tiempo en que ocurren, y su simetría debería ser perfecta en la medida en que la reconstrucción fuera igualmente perfecta. Al fin de cuentas, como afirma

${ }^{16}$ Poe, "The murders in the Rue Morgue", en op. cit., p. 263. 
su personaje William Legrand, nada puede ser cifrado por una mente humana que otra mente humana no pueda descifrar. ${ }^{17}$ El propio Poe cita a Novalis (1772-1801) con motivo de la reconstrucción del asesinato real y sin resolver de la joven Mary Cecil Rogers, ocurrido en 1841 en Hoboken, New Jersey, que convirtió en el tema de uno de sus cuentos y ambientó en el París de la época:

There are ideal series of events which run parallel with the real ones. They rarely coincide. Men and circumstances generally modify the ideal train of events, so that it seems imperfect, and its consequences are equally imperfect. $^{18}$

Estas series ideales de sucesos constituyen la reconstrucción de los hechos que se investigan y, lógicamente, cualquier falla en el seguimiento conduce a conclusiones desviadas de las reales en proporción directa de la equivocación cometida (según estuvo a punto de comprobar el mismo Legrand cuando el error de pulgadas cometido por su criado terminó desviándolo varias yardas del objeto de su búsqueda), motivo por el que es imprescindible allegarse toda la información posible y veraz para hacer un seguimiento satisfactorio del

${ }^{17}$ Poe, “The gold-bug”, en op. cit., pp. 118-119.

${ }^{18}$ Citado en Poe, "The mystery of Marie Rogêt", en op. cit., p. 314. asunto, y no limitarse a reflexionar en abstracto. El analista - dice Poecomo el jugador de cartas, "no se encierra en sí mismo", sino que, en silencio, "procede a acumular cantidad de observaciones y deducciones", incluyendo las procedentes de elementos externos al juego. ${ }^{19}$ De hecho, si a primera vista parece que nada cuenta la infinita variedad de la vida real que envuelve el hecho criminal, no es porque el caballero Dupin se solace en la abstracción, como podría suponer una concepción estereotipada de su carácter (por lo demás tan ampliamente difundida entre sus lectores más superficiales), como ocurre en Los mitos de la novela criminal, de Vázquez de Parga. ${ }^{20}$ Por el contrario, ante las circunstancias inciertas en que se encuentra sumergido antes de desvelar un misterio, si bien Dupin puede hacer conjeturas, no puede presentarlas más que como hipótesis a partir de los indicios recuperados durante la investigación, esperando no haber fallado en sus cálculos en lo que aguarda la confirmación promovida por él mismo a través de avisos periodísticos y visitas personales. No es verdad, como afirma Vázquez de Parga, que Dupin confiese proceder por conjeturas con respecto a la investigación en general, sino acerca

\footnotetext{
${ }^{19}$ Poe, "The murders in the Rue Morgue", en op. cit., p. 264.

${ }^{20}$ Salvador Vázquez de Parga, Los mitos de la novela policial, 1981, Barcelona, Planeta, pp. 36-39.
} 
de los elementos subjetivos asociados a los hechos patentes (perfectamente comprobados), de los cuales no se puede dar cuenta de la misma manera. ${ }^{21}$ Precisamente para no caer en el error de una conclusión gratuita en estos aspectos, Dupin es el primero en advertir acerca del lado subjetivo de sus consideraciones:

I will not pursue these guesses-for I have no right to call them moresince the shades of reflection upon which they are based are scarcely of sufficient depth to be appreciable by my own intellect, and since I could not pretend to make them intelligible to the understanding of another. We will call them guesses then, and speak of them as such. ${ }^{22}$

Por otra parte, es verdad también que esta manera de acercarse al conocimiento humanista y no solo de la naturaleza formaba parte de una tradición muy antigua y ampliamente reconocida en Europa, lo cual queda manifestado por la cita que el mismo Poe hace de sir Thomas Browne (1605-1682): "What song the Syrens sang, or what name Achilles assumed when he hid himself among women, although puzzling questions, are not beyond all conjecture". ${ }^{23}$ Esto era así

${ }^{21}$ Ibid., p. 38.

${ }^{22}$ Poe, "The murders in the Rue Morgue", en op. cit., p. 303.

${ }^{23}$ Según el epígrafe en Poe, "The murders in the Rue Morgue". porque, como hasta el día de hoy, la conjetura no era una especulación sin fundamento, sino una hipótesis basada en indicios.

Por lo demás, lejos de limitarse al escrutinio distante y abstracto de los hechos, su detective, como Poe mismo, nunca fue víctima de ese ennui, el hastío crónico que incapacita para la acción, del que sus detractores lo acusan para contraponerlo a la figura supuestamente más dinámica de Sherlock Holmes. Estos críticos olvidan que cuando está en condiciones de hacerlo, Dupin visita y revisa a conciencia con sus propios ojos los escenarios del crimen juzgando que es necesario proceder personalmente a un examen antes de formarse una opinión. ${ }^{24}$ Véase si no el minucioso escrutinio al que somete la habitación de las brutalmente asesinadas Madame L'Espanaye y su hija, así como los alrededores del inmueble; recuérdense, asimismo, las peligrosas visitas de inspección que hace a la casa del extorsionador " $D$ " en el caso de "La carta robada" para recuperar el documento que da nombre al relato.

Cuando en "El misterio de María Rogêt” Dupin realiza la pesquisa desde su casa es porque, en su afán por utilizar información verdadera (pero al encontrarse muy lejos del lugar del

\footnotetext{
${ }^{24}$ Poe, "The murders in the Rue Morgue", en op. cit., p. 285.
} 
crimen), el mismo Poe solo contaba con los periódicos para documentarse acerca del asesinato y no porque creyera realmente que bastaba con la reflexión en abstracto para resolver el caso:

The "mystery of Marie Roget" was composed at a distance from the scene of the atrocity, and with no other means of investigation than the newspapers afforded. Thus much escaped the writer of which he could have availed himself had he been upon the spot, and visited the localities. ${ }^{25}$

Así pues, con este recurso Poe no hacía sino prolongar en el texto el paralelismo de su misma falta de observaciones directas y, por lo mismo, requería una explicación para justificar este procedimiento no presencial en alguien que se encontraba en la ciudad donde había ocurrido el crimen. Por eso, a diferencia de la calle Morgue, donde Dupin se presenta al día siguiente de los hechos, en el caso de María Rogêt se impuso la necesidad narrativa de mencionar que cuando el detective se entera del asesinato ya habían transcurrido más de tres semanas desde la aparición del cadáver, lo cual, se entiende, volvía inútil la exploración directa de los sitios involucrados.

${ }^{25}$ Nota en Poe, "The mystery of Marie Rogêt", en op. cit., p. 314.

\section{Un método creativo basado en detalles}

Esto mismo nos hace dudar de Juan del Rosal cuando pretende caracterizar el método de Dupin descrito por Poe como un "razonar inteligentemente" para encontrar a su culpable, concibiendo la realidad conforme al esquema mental del investigador. ${ }^{26}$ De hecho, el mismo Dupin critica esta postura en los miembros de la policía parisina: "They consider only their own ideas of ingenuity; and, in searching for anything hidden, advert only to the modes in which they would have hidden it". ${ }^{27}$

Los procedimientos de Dupin son más complejos que eso, pues se ajustan a las circunstancias y características del crimen que debe solucionar. Eso es precisamente lo que hace que en la figura de Edgar Allan Poe confluyan diferentes esquemas de la novela policiaca que serán tan explotados años después por sus sucesores: 1) la novela de problema imposible (principalmente el crimen de cuarto cerrado), 2) la solución del problema sin salir de casa a partir de información de segunda mano (también conocida como "detective de sillón”), y 3) el método de engaño

\footnotetext{
${ }^{26}$ Juan del Rosal, Crimen y criminal en la novela policiaca, 1947, Madrid, Instituto Editorial REUS, p. 58.

${ }^{27}$ Poe, “The purloined letter", en op. cit., p. 404.
} 
psicológico. ${ }^{28}$ Estos esquemas se vinculan a las variantes de crimen que Agata Christie denominará luego "desde dentro" y "desde fuera". ${ }^{29}$ Cada uno tiene una complejidad distinta y requiere un procedimiento de abordaje también diferente.

De esta manera en los crímenes desde dentro, con un criminal incluso conocido, lo que importa es conocer los caracteres de su mente para determinar sus recursos y la lógica de su proceder, calibrar su agudeza mental para intentar resolver el misterio, ${ }^{30}$ mientras que en los crímenes desde fuera, cada rasgo del crimen, cada circunstancia que lo rodea representan indicios que apuntan hacia el carácter o circunstancias del malhechor mismo para realizar su búsqueda. Precisamente por ello, porque "exceden los límites de las meras reglas", ${ }^{31}$ para Poe la habilidad del analista depende de su capacidad para acudir a las circunstancias específicas que envuelven los hechos.

Para Carlo Ginzburg, que toma la idea del historiador del arte Aby

${ }^{28}$ César E. Díaz, La novela policiaca, 1973, Barcelona, Acervo, pp. 21-22.

${ }^{29}$ Agata Christie, "El asesino de la guía de ferrocarriles", en Obras completas I, 3a. ed., 1984, Barcelona, Orbis, traducción de DIORKI traductores, p. 434.

${ }^{30}$ Poe, "The purloined letter", en op. cit., pp. 404 y $409-410$.

${ }^{31}$ Poe, "The murders in the Rue Morgue", en op. cit., p. 264.
Warburg, ${ }^{32}$ y María Elena Bitonte, que la remonta a Gustave Flaubert (1821-1880), ${ }^{33}$ la verdad se encuentra en los detalles. Edgar Allan Poe, en cambio, afirma que la tendencia a buscar la verdad en los detalles conduce al error. ${ }^{34}$ Enunciados que solo aparentemente son contradictorios, en realidad llevan a lo mismo en el fondo.

Para Ginzburg y Bitonte, son los pequeños indicios los que, rastreados e interpretados con precisión, llevan al todo que los ha producido. Para Poe, el equívoco no consiste en la búsqueda de los detalles per se, sino en quedarse en ellos sin encontrar el común denominador que los asocia y que les da sentido: ver los árboles sin ver el bosque. Por eso puede criticar al legendario ladrón y luego detective francés EugèneFrançois Vidocq (1775-1857), primer director de la Sûreté Nationale y uno de los primeros investigadores privados profesionales de la historia, del cual Dupin afirma que

was a good guesser, and a persevering man. But, without educated thought, he erred continually by the very intensity of his investigations. He impaired his vision by holding the object too close. He might see,

${ }^{32}$ Citado en Carlo Ginzburg, op. cit., p. 138.

${ }^{33}$ María Elena Bitonte, loc. cit.

${ }^{34}$ Poe, "The mystery of Marie Rogêt", en op. cit., p. 388. 
perhaps, one or two points with unusual clearness, but in so doing he, necessarily, lost sight of the matter as a whole. ${ }^{35}$

Para Poe, en voz de su detective, la exuberancia en el ingenio, aquel que raya incluso en la fantasía, lleva desventuradamente a inventar las respuestas, en lugar de a encontrarlas, debido a un exceso de profundidad. Al final de cuentas, los indicios están a la vista, son invariablemente superficiales, ${ }^{36} \mathrm{y}$ por lo mismo perceptibles, pero hay que saber dónde buscar y cómo reconocerlos, pues es muy común que lo más difícil de notar sea lo más evidente. ${ }^{37} \mathrm{Y}$ es 10 más evidente, el indicio, lo que debe orientar la percepción hacia lo menos evidente, el todo del que forma parte. ${ }^{38}$

Basándose en estos indicios, al igual que el caballero Dupin al reconstruir la línea de pensamientos de su fiel asociado en el célebre pasaje de la calle cercana al Palais Royale (que lo llevan del vulgar encontronazo con un frutero hasta una serie de eruditas consideraciones cosmogónicas y chismes de la escena teatral de la ciudad), Poe no tiene empacho en hablar de su habilidad para repasar retrospectivamente los hechos, aun

${ }^{35}$ Poe, "The murders in the Rue Morgue", en op. cit., p. 284.

${ }^{36}$ Loc. cit.

${ }^{37}$ Poe, “The purloined letter", en op. cit., p. 411.

${ }^{38}$ María Elena Bitonte, loc. cit. cuando se limite a los pasos de la composición literaria. ${ }^{39}$

\section{La heurística creativa como falso método indicial}

En Edgar Allan Poe, el método es necesario incluso para la creación artística; no obstante, al revés del método cinegético, aquí no se trataba de un proceso de descubrimiento, en el que se partiera de indicios en la búsqueda de la realidad que los explicara, sino del planteamiento de una explicación o desenlace en la que convergieran posteriormente todas las pistas: "It is only with the dénouement constantly in view that we can give a plot its indispensable air of consequence, or causation, by making the incidents, and especially the tone at all points, tend to the development of the intention". ${ }^{40}$

Se trataba, pues, de un método, de una heurística creativa, no el "sutil frenesí" o la "intuición extática" con los que los poetas de la época buscaban rodear sus trabajos como una manera de conferirles valor al equipararlos a una revelación de índole sobrenatural. ${ }^{41}$ Para Poe, la explicitación del método era una muestra de inteligencia y previsión meramente humana que emparentaba su trabajo

\footnotetext{
${ }^{39}$ Poe, "The philosophy of composition", en op. cit., p. 159.

${ }^{40}$ Ibid., p. 157.

${ }^{41}$ Ibid., p. 159.
} 
con el de las ciencias apoyadas por el cálculo matemático. Para ser científico, el razonamiento que llevara a la producción de una obra literaria de calidad no debía confiarse a la intuición o al azar, sino realizarse "with the precision and rigid consequence of a mathematical problem", ${ }^{2}$ comenzando por el conocimiento del todo que se pretendía lograr, para luego retroceder hasta el inicio del fenómeno creativo, hacia las partes con las cuales se buscaba recrearlo cronológicamente. ${ }^{43}$

¿Ocurría así con sus cuentos de raciocinio? ¿Partía Poe del diseño previo de un desenlace planeado para causar un efecto, y a partir de ahí determinaba los indicios que debían impulsarlo paso a paso hasta su explicación? Sin duda, y por lo mismo el resultado de "La carta robada" y "Los asesinatos de la calle Morgue" están tan ampliamente logrados (igual que en "El escarabajo de oro"), mientras que en el caso de "El misterio de María Rogêt", ajeno a su diseño final en tanto que fue un asesinato real que nunca se resolvió, presenta un desenlace oscuro aunque pretendidamente exitoso: porque el seguimiento de un caso real a partir de las pistas encontradas en los periódicos, aunque meticulosamente realizado, "sobreexcitado quizás en algunos aspectos, insuficiente en otros", no

${ }^{42}$ Ibid., p. 160.

${ }^{43}$ Ibid., pp. 157-158. garantizaba la solución correcta, por más "extrañamente convincente" que resultara su hipótesis. ${ }^{44}$ Desde luego, la invención no es igual que la búsqueda, y los indicios difícilmente son tan límpidos y concluyentes en la segunda como lo son en la primera.

Como señalaron los críticos literarios en su momento, la eficacia de la investigación en "Los asesinatos de la calle Morgue" tenía más que ver con que Poe lo hubiese escrito "hacia atrás", con la solución pensada de antemano, que con el verdadero genio investigador. El mismo Poe se preguntaba: “¿Dónde radica el ingenio [...] de desenmarañar un enredo que uno mismo ha creado con el expreso deseo de desenmarañarlo?" 45

En "El misterio de María Rogêt" no existía esa posibilidad, pues tratándose de un asesinato verdadero tenía que desentrañarse de atrás hacia adelante en un momento en el que la policía no estaba más cerca de resolverlo que en julio de 1841. Pero Poe se aseguró en el texto una vía de escape: el suyo era un cuento basado en paralelismos, no en coincidencias exactas. Trasladar la acción a París le permitía apartarse de los rígidos hechos del caso y "si

\footnotetext{
${ }^{44}$ Amy Gilman Srebnick, The misterious death of Mary Rogers: Sex and culture in nineteenthcentury New York, 1997, Nueva York, Oxford, Oxford University Press, p. 110.

${ }^{45}$ Citado en Daniel Stashower, Edgar Allan Poe y el misterio de la bella cigarrera, 2010, Barcelona, Alba, traducción de Miguel Temprano García, s/p.
} 
alguno de los detalles no coincidía con los de la tragedia neoyorquina, podía achacarlo al cambio de escenario". ${ }^{46}$ De este modo, no era imputable al autor si la sucesión de los acontecimientos, distorsionados por cualquier pequeño fallo intermedio, terminaban alejándose inexorablemente de los hechos del caso original. ¿No funcionaba así el epígrafe tomado de Novalis para su cuento? La inexactitud en los desenlaces de dos hechos tan similares no era inducida por el error de su análisis, sino que eran producto de la misma alteridad.

\section{Conclusión}

La exuberante imaginación poética de Edgar Allan Poe confirma la búsqueda de la época por hacerse de métodos confiables para el análisis de los enigmas del mundo real (al menos, tan real como lo suponía el positivismo comptiano), lo cual, desde finales del siglo XVIII, propendía a la aplicación social de teorías pseudocientíficas como la fisiognomía y la frenología, así como a prácticas tan poco confiables como el mesmerismo y la grafología en su intento de conocer y, en la medida de lo posible, prever las tendencias de la mente humana.

No obstante, antes que investigador, Poe se nos presenta como inventor de soluciones detalladas y verosími-

\footnotetext{
${ }^{46}$ Stashower, loc. cit.
}

les para complejos relatos de fantasía. En su concepción de que lo científicomatemático y lo imaginativo-poético constituían una unidad, y del hecho de que el hombre no puede crear de la nada, pensaba que la actividad de la imaginación consistía esencialmente en buscar nuevas conexiones entre lo ya existente. ${ }^{47}$ Las mojoneras para guiarse entre los hechos y establecer sus vínculos son sus indicios, para el manejo de los cuales proponía a nivel literario un método que bien podría denominarse "heurística creativa".

Si bien es cierto que la palabra "heurística", que suele asociarse con el descubrimiento, implica tam-

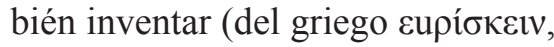
"hallar, inventar"), y resulta claro, por lo tanto, que la heurística creativa, y más todavía la de narrativa detectivesca, comparte con la investigación científica una serie de procedimientos, también es verdad que estos se aplican a la inversa. Los métodos de las ciencias sociales y los de la creación literaria no son los mismos y precisamente por ese motivo los argumentos a veces sostenidos con respecto a las semejanzas entre la literatura y las ciencias sociales en cuanto a su capacidad para conocer el mundo necesitan continuar bajo la lupa.

${ }^{47}$ Clemens A. Franken Kurzen, Crimen y verdad en la novela policial chilena actual, 2003, Santiago de Chile, Universidad de Santiago de Chile, pp. 25-26. 